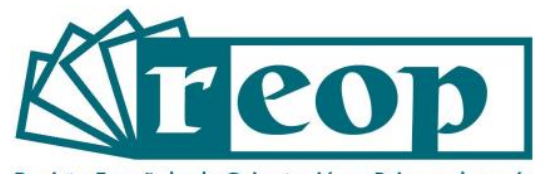

Revista Española de Orientación y Psicopedagogía

\title{
Pantoja Vallejo, A. (Coord.) (2020). Buenas prácticas en la tutoría universitaria. Editorial Síntesis, 243 páginas. ISBN: 9788413570990
}

El libro es la consecuencia de un trabajo de investigación llevado a cabo por diferentes profesionales de la pedagogía, de la orientación y de la tutoría universitaria. En el mismo se destaca la importancia del tutor, junto con la buena planificación, diseño e implementación del Plan de Acción Tutorial (PAT) y la utilización de los servicios especializados de tutoría en la universidad.

El coordinador de este libro, Antonio Pantoja, junto con profesores de referencia en la temática, que imparten docencia en diferentes universidades españolas e internacionales, presentan, a lo largo de once capítulos, distintas técnicas, recursos y estrategias enmarcadas dentro de la tutoría universitaria.

Se inicia el libro con un capítulo dedicado al tutor, "El tutor como agente de cambio y las buenas prácticas", destacando el rol del buen profesor-tutor universitario, pues una de sus funciones principales es implicar al alumnado, tanto en su proceso de aprendizaje como en su desarrollo profesional. Para ello, es fundamental tener conocimientos psicopedagógicos y del mercado laboral, junto con las oportunidades profesionales, capaces de favorecer las buenas prácticas tutoriales en la universidad. La obra prosigue con el capítulo dos, "La universidad como espacio inclusivo", en el que los autores se centran en la inclusión del alumnado con discapacidad en las aulas universitarias, destacando los diferentes retos que este proceso supone, como puede ser la capacitación del profesorado en atención a la diversidad. Por otro lado, los autores presentan la normativa que respalda los derechos de este alumnado, a la vez que destacan la importancia de la tutoría como estrategia de mejora de la inclusión. Asimismo, encontramos un tercer capítulo, "El dominio de las técnicas tutoriales básicas", donde se destacan diversas técnicas e instrumentos necesarios en la tutoría, como son la observación, la entrevista, el debate, el uso de cuestionarios, el portafolio, el árbol de problemas y las técnicas DAFO.

Avanzando en la lectura, se dedica el cuarto capítulo a los "Entornos de aprendizaje para una acción tutorial enfocada en la docencia". Las autoras señalan la importancia de formar a profesionales capaces de adaptarse a las demandas de la sociedad, por ello, proponen crear entornos flexibles desde la universidad y dan las claves metodológicas para llevarlo a cabo. Desde esta perspectiva, el capítulo cinco aborda la "Atención a las dificultades de aprendizaje" en dos vertientes, por un lado, hace referencia a las dificultades de aprendizaje en el alumnado universitario sin diagnóstico previo, y por otro, se centra en el alumnado que presenta trastornos de aprendizaje antes del acceso a la universidad, describiendo los principales problemas e indicando soluciones prácticas. A continuación, el capítulo seis, se centra en el "Aprendizaje autorregulado", en él los autores describen en qué consiste el mismo, presentando estrategias y 
técnicas de intervención para su mejora en el contexto universitario. Seguidamente, en el capítulo siete, "Educación emocional en la orientación y tutoría universitaria", se describen los términos y competencias que persigue la educación emocional, aspecto a tener en cuenta para trabajarlo mediante la tutoría universitaria.

Ya en el capítulo ocho de esta obra, "Orientación para la construcción y gestión del proyecto profesional", las autoras detallan los factores que intervienen en la construcción de la identidad personal y laboral, aspectos de suma importancia en esta etapa universitaria, y además destacan la utilidad del modelo CCP-Construyendo mi Carrera Profesional, describiendo las fases que lo forman. En esta misma línea se sitúan el capítulo nueve dedicado a las "Técnicas y estrategias para la búsqueda de empleo" y el diez, "Transición al mundo del empleo", en el que sus autores determinan estrategias para analizar el mercado de trabajo, la inserción sociolaboral y la toma de decisiones que establecen el futuro profesional, así como el proceso de aprendizaje que supone este transcurrir. De igual forma, se describen las relaciones entre la universidad y el mundo laboral. El libro termina con el capítulo once, "El papel de las tecnologías en el proceso tutorial", donde se señala la importancia de las TIC, por un lado, como sustento de la innovación docente, $y$, por otro, como base fundamental en la tutoría universitaria, al trabajarse mediante las mismas sus diferentes vertientes, es decir, el plano académico, el profesional y el personal.

La lectura de este libro, como se ha comentado líneas atrás, permite realizar una reflexión sobre el marco de una nueva universidad y de un nuevo modelo docente-tutor, en un mejor conocimiento de las áreas de intervención en las que se basa el profesorado para dar respuesta a las necesidades de sus alumnos tutelados. Se trata de una obra muy recomendable, bien fundamentada y contextualizada, que presenta distintas metodologías, técnicas y estrategias de actuación, al mismo tiempo que ofrece, desde la perspectiva de profesores especialistas, un conocimiento profundo de lo que son las buenas prácticas en la tutoría universitaria.

Nuria González Castellano

Becaria FPU

Miembro del Grupo de Investigación IDEO

Universidad de Jaén

Cristina Arazola Ruano

Miembro del Grupo de Investigación IDEO

Universidad de Jaén

\section{Cómo citar esta recensión:}

González Castellano, N, y Arazola Ruano, C. (2020). Pantoja Vallejo, A., Coord., 2020, Buenas prácticas en la tutoría universitaria, Editorial Síntesis, 243 páginas. ISBN: 9788413570990 [Reseña] Revista Española de Orientación y Psicopedagogía, 31(3), 170-171. https://doi.org/10.5944/reop.vol.31.num.3.2020.29267 